\title{
Tulpas and Mental Health: A Study of Non-Traumagenic Plural Experiences
}

\author{
Jacob J. Isler ${ }^{*}$ \\ Department of Communication, University of Texas at Austin, Austin, Texas, United States \\ *Corresponding author: isler@utexas.edu
}

\begin{abstract}
Current models of mental health rely heavily on the assumption that only one agent of self exists in every one brain. Deviations from this model of singularity in mind are heavily stigmatized and often considered disordered. This paper opposes this bias by analyzing one form of plurality in consciousness: tulpamancy. Tulpamancy is a collection of meditative techniques used to create and interact with tulpas, which are experienced as fully autonomous and conscious entities within the mind. Research defining the relationship between tulpamancy and mental health is expanded on by analyzing the results of surveys conducted on the online tulpa community. The questionnaires investigate two associations previously found in members of the tulpa community. First, the prevalence of mental illness, which exists in over $50 \%$ of the population. Second, the reports of improvements in mental health and cognition, especially amongst those diagnosed with a mental or neurodevelopmental disorder. Study results reinforce the correlation between tulpa creation and perceived improvements in mental health. There is likely no causal relation between tulpamancy and the development of psychopathology. Tulpas are an experience of plurality that seem to coexist with optimal functionality, happiness, and mental health.
\end{abstract}

Keywords: tulpas, tulpamancy, imaginary friends, identity, multiple identities, plurality, multiplicity, dissociative identity disorder, multiple personality disorder, meditation

Cite This Article: Jacob J. Isler, "Tulpas and Mental Health: A Study of Non-Traumagenic Plural Experiences.” Research in Psychology and Behavioral Sciences, vol. 5, no. 2 (2017): 36-44. doi: 10.12691/rpbs-5-2-1.

\section{Introduction}

In medicine, society, and our personal biases, there exist certain presumptions about what is optimal for health, functionality, and happiness. One such assumption is the requirement that, for every one brain and body, there ought to be one identity. The words "plurality" and "multiplicity" denote deviations from this model: multiple identities coexisting in one mind.

Dissociative Identity Disorder (DID) is one such experience of plurality. It is a condition characterized by derealization, amnesia, and the trauma that causes its development [1,2]. However, rather than citing these dysfunctions, mental health professionals frequently emphasize the plurality as being what makes DID a disorder. At the time of writing, Psychology Today has the top Google search result for Dissociative Identity Disorder. The introductory article implies that all experiences of multiplicity are pathological. "Dissociative Identity Disorder (DID) is a severe condition in which two or more distinct identities, or personality states, are present inand alternately take control of-an individual” [3]. Here, DID is not branded by its negative symptoms like most disorders are. Rather, this definition suggests that the problem starts and ends with the plurality.

The definition of a mental disorder is a set of behaviors that causes harm or dysfunction [4]. A violation of a norm, on the other hand, should not be the basis for a diagnosis.
In the medical literature, DID seems to be an exception to this rule. Until the DSM-V, there was no requirement of distress or impaired functioning in the diagnosis of DID. ${ }^{1}$ "Unlike other disorders, dissociative identity is deemed a disorder and thereby dysfunctional, purely on the basis that those who experience it have a self that is not singular." [5]

Despite this stigma, online groups have formed around plurality, upholding it as a non-disordered variant of human cognition. In 2010, a community sprouted over a practice colloquially dubbed "tulpamancy." Tulpamancy is the practice of creating and interacting with tulpas, which are experienced as fully autonomous and conscious entities within the mind. In this paper, the word "host" is used interchangeably with "tulpamancer" to describe someone who creates and interacts with tulpas. Examination will purport tulpas as a healthy experience of plurality and an argument against the stigmatization of multiple identities.

\footnotetext{
${ }^{1}$ The DSM-IV and DSM-IV-TR do not list distress or dysfunction as diagnostic criteria for Dissociative Identity Disorder.

"Diagnostic Criteria for Dissociative Identity Disorder:

A. The presence of two or more distinct identities or personality states (each with its own relatively enduring pattern of perceiving, relating to, and thinking about the environment and self).

B. At least two of these identities or personality states recurrently take control of the person's behavior.

C. Inability to recall important personal information that is too extensive to be explained by ordinary forgetfulness.

D. The disturbance is not due to the direct physiological effects of a substance (e.g., blackouts or chaotic behavior during Alcohol Intoxication) or a general medical condition.” [6]
} 


\subsection{Literature Review}

The majority of media surrounding tulpas and non-traumagenic plural phenomena has been limited to poorly researched sensationalism. Its scientific accounts were nonexistent until 2015, when Professor Samuel Veissiere of McGill University published Varieties of Tulpa Experiences [7]. In the paper, Veissiere overviews the results of a year-long observational study on the tulpa community. Data on the demographic profile of tulpamancers, socio-cultural aspects of the tulpa community, and the experiences of tulpamancers were collected through a series of opt-in surveys and interviews.

Veissiere found that tulpas are perceived to be entities distinct from one's own thoughts, with over a third of hosts reporting that their tulpas felt as real as any physical person. This is achieved in part through tulpas seeming to be independent in their emotions, cognition, and opinions. They are experienced through a mix of auditory, visual, and somatic visualizations and hallucinations. Possession, a technique that allows a tulpa to temporarily command of the body, and switching, in which the host dissociates to have an out-of-body experience while the tulpa controls the body, are widely used. There are similarities between these advanced tulpamancy techniques and the experiences of DID diagnosed folk, namely having multiple identities and dissociating from the body's actions. However, the absence of amnesia, depersonalization, and other traumagenic symptoms in most tulpamancers make these techniques a reportedly positive and mutually enjoyable experience.

On personality tests, the majority of Veissiere's sample tested as being shy $(n=74)$ and having few avenues for social interaction. This coincides with another of Veissiere's findings: tulpas are made in hope of becoming a close companion. In the community, tulpa creation is seen as a way to build a relationship with someone that can understand, accept, and bond with you on a level beyond what is usually possible with another person.

Despite their (on average) limited social lives, Veissiere found his sample to be highly imaginative, cerebral, and articulate, even scoring above average on theory of mind and empathy tests. This held consistent even among tulpamancers on the autism spectrum ${ }^{2}(n=11)$, who, despite their condition, showed no hindrances in these areas.

Veissiere unveiled two more associations between tulpas and mental health. Foremost, an extremely high frequency of clinical diagnoses: in his sample $(n=24)$, $25 \%{ }^{3}$ were diagnosed with Asperger's syndrome, $21 \%$ with Attention Deficit Disorders, and 18\% with General Anxiety Disorder, to name a few. This is compared to the figures of $<1 \%, 11 \%$, and $3 \%$, respectively, in the general population of the United States [9,10,11]. Secondly, Veissiere found that tulpas were reported to cause improvements in mental disorders, with 94\% $(n=33)$ of respondents expressing that taking up tulpamancy had "made their condition better." Veissiere elaborates on

\footnotetext{
2 The author does not uphold "low empathy" as being the cause of autism or something possessed by all people on the spectrum. Even so, research continues to show that, on average, those on the spectrum perform lower on theory of mind assessments, including adults of an almost identical demographic of Veissiere's sample [8].

${ }^{3}$ All percentages are rounded to the nearest integer.
}

one example of this. In his sample, over half of the tulpamancers on the autism spectrum reported that their tulpas enhance their ability to read and understand others. These claims support the previously mentioned tests that showed no impairments in theory of mind or empathy amongst tulpamancers on the autism spectrum.

Veissiere's study remains the only published, peerreviewed research conducted on the tulpa community.

\subsection{Objective}

This study investigates the aforementioned associations: 1) the high frequency of disorders among tulpamancers, and 2) the reports of psychological improvements related to tulpas. The aim is to clarify the existence of these associations and identify their causes.

While Veissiere showed that there seemed to be a relationship between tulpamancy and mental health, the reasons and nature of it are still a mystery. The noted associations have a plethora of possible explanations. For example, the high frequency of mental illness among tulpamancers could be rooted in a causal relationship between tulpas and psychopathology. More likely, tulpamancy could merely be more appealing or have more exposure to those with a clinical diagnosis.

Regarding the improvements in mental illness reported by tulpamancers, it would be presumptive (given the current evidence of a single opt-in questionnaire whose statistics are based on as little as 11 respondents) to claim the cause is plurality being therapeutic in itself. The practice of meditation has many benefits on its own [12], and its frequent use amongst tulpamancers may be responsible for these improvements rather than something unique to tulpas. Forming positive relationships through the tulpa community could also explain the association. Finally, there is the possibility of tulpamancy itself having therapeutic qualities.

The study addresses all these possibilities in order to hypothesize the cause of phenomena associated with tulpas.

\section{Methods}

This study was a survey-based and observational. A series of questionnaires were used to gather data from users on several of the most popular tulpamancy forums and chat websites. Unlike Veissiere's, these surveys were not publicly posted, opt-in ones-- it was only available to registered users of tulpa sites. At the time, the tulpa community was based on four websites: http://reddit.com/r/tulpas (a subreddit), http://tulpa.info (a forum and IRC), http://tulpa.io (a forum), and http://tulpa.im (an IRC). The tulpa subreddit was excluded from the study due to an inability to view a list of its users. The user bases of the http://tulpa.info IRC, http://tulpa.io forums, and http://tulpa.im IRC were the studied population.

A total of 365 accounts existed on these sites on the survey request date (January 13, 2016). These accounts were sent a message requesting their contribution to the survey, and participation was limited to individuals who had received this message. 
Before completing the survey, participants gave informed consent and agree to the disclosure and publication of their responses. The purpose of the study was outlined on this consent form. The survey consisted of 58 questions and was estimated to take ten minutes to complete. This research being unfunded, no compensation or incentive was offered to participants. Responses were anonymous. The questionnaire was divided into four sections: relationship to the tulpa community, experiences in tulpamancy, mental health, and demographic information. Questions were predominantly Likert scales or polar.

\subsection{Sample Demographic}

Out of the 365 survey requests sent, a total of 63 responses were submitted. One submission was removed because the respondent selected that they had not practiced tulpamancy and did not have a tulpa, making the final response rate $17 \%$.

$88 \%$ of the sample ${ }^{4}$ aged between 16 and 25, with average age of 21 . $74 \%$ classified themselves as Caucasian, with the other most frequent identities being Multiracial (11\%), Asian (5\%), and Black (3\%). Regarding gender, $59 \%$ of respondents identified as male, $29 \%$ as female, and $12 \%$ as "other." A total of 16 nationalities were represented in the sample, with the United States making up 58\% of the responses (Table 1).

Table 1. Nationality of Tulpamancers $(n=55)$

\begin{tabular}{lc}
\hline Country & Frequency \\
\hline United States & 32 \\
United Kingdom & 5 \\
Australia & 3 \\
Canada & 2 \\
Mexico & 2 \\
New Zealand & 1 \\
Belarus & 1 \\
Poland & 1 \\
Belgium & 1 \\
Germany & 1 \\
Italy & 1 \\
Denmark & 1 \\
Singapore & 1 \\
Austria & 1 \\
Bosnia and Herzegovina & 1 \\
Ireland & 1 \\
\hline
\end{tabular}

The remainder of Section 2 is an overview of the questions of greatest significance to the conclusions. In addition to their stated purpose, each question underwent a thorough cross-sectional analysis to find any associations between responses to different questions. All noteworthy relationships (or lack thereof) are overviewed in Section 3.4.

\subsection{Experiences in Tulpamancy}

Survey participants were confirmed to be practitioners of tulpamancy by answering the question, "Does your system practice tulpamancy and/or have a tulpa?” with the

\footnotetext{
${ }^{4}$ The statistics presented in sections 3.1, 3.2 and 3.4 are derived from between 62 and 53 responses. The statistics presented in section 3.3 are derived from between 27 and 32 responses unless stated otherwise.
}

option yes and no. Respondents who answered "no" skipped the subsequent questions and were directed to the end of the survey. Respondents who answered "yes" were directed to more questions inquiring their specific practices and experiences with tulpas.

To investigate the effect of meditative practices often performed alongside tulpamancy, the survey asks: "Please select all the techniques that are/ have been used by your system for tulpamancy", with meditation and hypnosis being among the possible responses.

To explore how individual goals and the relationship one forms with their tulpa impacts their overall experience, the survey asked, "What relationships exist between [you and your] tulpa(s)?" and "If your tulpas came to be through conscious effort and/or forcing ${ }^{5}$, for what purpose did you create them?". Both questions have similar response options that included, "Friends or companions, "A romantic relationship or significant other," "Curiosity or experimentation," "To become a part of a community," and "Self-Improvement or life/mental health benefits."

\subsection{Relationship to the Community}

To probe how one's experiences and relationship with the tulpa community affected the perceived impact of tulpas, various questions queried the participant's opinions and commitment towards the online community. The survey asked: "On a scale of 1--9, how would you describe your involvement with the tulpa community?" with options like "7: I regularly view or post in forums, blogs, or chat rooms of the community."

It later asked: "How would you describe your opinion of the parts of the tulpa or plural communities you regularly interact with?" followed by possible responses, "Very negative," “Negative,” "Neutral,” "Positive,” and "Very positive."

\subsection{Associations with Mental Illness}

The relationship between tulpamancy and mental health was investigated through several questions in the survey. Participants were asked to select yes or no to the question: "Have you been diagnosed with a mental or neurodevelopmental disorder?”. If “yes” was selected, the participant would be directed to more questions regarding the relationship between their condition(s) and their experiences with tulpas. If "no" was selected, they would skip those questions and be directed to the next portion of the survey.

To inquire the potential of there being a causal link between tulpamancy and mental illness, these respondents were asked: "Were these diagnosed before or after you began practicing tulpamancy?” To follow up this question, the next one asked: "If any of your disorders were diagnosed after you started tulpamancy, do you think this practice contributed to the diagnosis?" Response categories were "Yes, significantly," "Yes, somewhat," "Unknown," "No,” and "Not applicable."

It is also possible that the high volume of psychopathologies in tulpamancers is caused by the practice being especially

\footnotetext{
${ }^{5}$ In the tulpa community, "forcing” refers to the meditative techniques used to create and interact with tulpas.
} 
appealing towards those diagnosed with a condition. To address this, the survey asked: "Do you feel that your condition(s) influenced your decision to begin practicing tulpamancy?” with subtext reading “Did your disorder(s) make you want to have a tulpa?" Respondents were given the options: "Yes, strongly," "Yes, somewhat," "Unknown," and "No."

Continuing this line of thought, the next question read: "How do you feel the symptoms of your disorder(s) affect the desirability of tulpamancy?" with the subtext "Does your condition make tulpamancy a more appealing or enjoyable practice?” Respondents were requested to select what best described their experiences (for example, "They make tulpamancy a significantly more desirable practice”).

Later questions explored the relationship between tulpas and perceived mental health. The question "How do you feel tulpamancy has affected your condition(s) or ability to cope with them?" requested respondents to select what best described their experience, such as "It has significantly improved my condition or ability to cope with it."

The survey also queried a specific phenomenon that could help explain the association between tulpas and perceived improvements: "Does your tulpa seem to be independent of your disorder(s)?" The question subtext read: "For example, if a host has ADHD, a tulpa that is independent of their host's disorders may not struggle with hyperactivity and attention. Essentially, does your tulpa seem to be unaffected by your disorder(s)?" Respondents were given the options: "Yes, strongly," "Yes, somewhat," "Unknown," and "No."

The remaining inquiries were given to all survey participants (not just those diagnosed with a psychopathology). Three significant questions were, "How do you feel plurality has had an impact on your social life?", "How do you feel plurality has had an impact on your mental health?", and "How do you feel plurality has had an impact on your overall life?”. Response options for these three questions were "It has had a significantly positive impact," "It has had a somewhat positive impact," "It has had a neutral impact," "It has had a somewhat negative impact," "It has had a significantly negative impact," and "It has not had an impact."

Each section ended with the request, "If you would like to elaborate on any of your answers on this page, please do so below." The survey concluded with questions inquiring the age, gender, country of residence, and race of the respondent.

\section{Results}

Survey findings of greatest significance to the investigated associations and conclusions are presented below.

\subsection{Experiences in Tulpamancy}

Most respondents reported doing meditation (54\%), hypnosis (25\%), or both (21\%) as part of their tulpamancy practice, with $31 \%$ of the sample reporting that they took part in neither.
Responses to the question, "For what purpose did you create [your tulpas]?” revealed that tulpas are most frequently created in pursuit of companionship (72\%). Results from the question, "What relationships exist between [you and your] tulpa(s)?" shows that this is achieved in most cases, with $78 \%$ of respondents stating that their relationship with their tulpa is friendship and $31 \%$ describing it as romantic.

\subsection{Associations with Mental Illness}

32 of 57 respondents (56\%) reported being diagnosed with a mental or neurodevelopmental disorder, with the most common diagnosis being Depressive Disorders, Anxiety Disorders, and Autism Spectrum Disorder Table 2).

Table 2. Frequency of Mental Disorders (n=32)

\begin{tabular}{lc}
\hline Diagnosis & Frequency \\
\hline Depressive disorders & 14 \\
Anxiety disorders & 10 \\
Autism Spectrum Disorder & 9 \\
Bipolar Disorder & 5 \\
ADHD & 4 \\
OCD & 3 \\
PTSD & 2 \\
Dissociative Disorders & 2 \\
Stress Response Syndrome & 1 \\
DCD & 1 \\
Dyslexia & 1 \\
Torrettes & 1 \\
\hline
\end{tabular}

$79 \%$ of these diagnoses occurred before the creation of tulpas. Even among those who were diagnosed after (7 respondents), all but one stated that tulpas did not contribute towards their diagnosis. The one respondent who did associate tulpa creation and their diagnosis elaborated in their response, saying that tulpamancy helped them identify their DID and PTSD symptoms, which were rooted in events predating their discovery of tulpamancy.

Two thirds of respondents with a diagnosis $(n=32)$ reported that their decision to begin practicing was either somewhat (33\%) or significantly (33\%) furthered by their condition. An almost identical ratio of respondents stated that their condition made tulpamancy a more desirable practice, with $37 \%$ citing a significant positive influence, $37 \%$ claiming a somewhat positive influence, and the remainder noting "no or neutral impact".

Similarly, most of these respondents reported that their tulpas had a significant (34\%) or somewhat positive (44\%) impact on their disorder(s) and/or ability to cope with them, with the remainder selecting "neutral or no impact."

The majority of tulpas were noted to be independent and unaffected by their host's condition to some degree. $37 \%$ report significant independence, $48 \%$ report some independence, and 15\% report no independence.

Most respondents reported tulpamancy having a positive impact on their mental health (Table 3) and overall life (Table 4), with "Neutral or no impact" being the most frequent response regarding the impact of tulpas on social life (Table 5). 
Table 3. Impact of Tulpas on Mental Health $(n=59)$

\begin{tabular}{lcc}
\hline Type of Impact & Frequency & Percentage \\
\hline Significant positive impact & 21 & $36 \%$ \\
Somewhat positive impact & 25 & $42 \%$ \\
Neutral or no impact & 13 & $22 \%$ \\
Somewhat negative impact & 0 & $0 \%$ \\
Significant negative impact & 0 & $0 \%$ \\
\hline
\end{tabular}

Table 4. Impact of Tulpas on Overall Life $(n=57)$

\begin{tabular}{lcc}
\hline Type of Impact & Frequency & Percentage \\
\hline Significant positive impact & 29 & $51 \%$ \\
Somewhat positive impact & 23 & $40 \%$ \\
Neutral or no impact & 5 & $9 \%$ \\
Somewhat negative impact & 0 & $0 \%$ \\
Significant negative impact & 0 & $0 \%$
\end{tabular}

Table 5. Impact of Tulpas on Social Life $(n=56)$

\begin{tabular}{lcc}
\hline Type of Impact & Frequency & Percentage \\
\hline Significant positive impact & 8 & $14 \%$ \\
Somewhat positive impact & 19 & $33 \%$ \\
Neutral or no impact & 28 & $49 \%$ \\
Somewhat negative impact & 1 & $2 \%$ \\
Significant negative impact & 0 & $0 \%$ \\
\hline
\end{tabular}

\subsection{Relationship to the Community}

The distribution of involvement in the tulpa community amongst respondents loosely resembles a bell curve, the peak being on " 3 : I may view a blog, thread, or forum once in a while" (Table 6).

Table 6. On a scale of 1--9, how would you describe your involvement with the tulpa community? $(n=56)$

\begin{tabular}{lcc}
\hline Level of Involvement & Frequency & Percentage \\
\hline $\begin{array}{l}\text { 1: I am not involved } \\
2\end{array}$ & 5 & $9 \%$ \\
$\begin{array}{l}\text { 3: I may view a blog, thread, or forum once } \\
\text { in awhile }\end{array}$ & 18 & $32 \%$ \\
4 & 10 & $18 \%$ \\
$\begin{array}{l}\text { 5: I may occasionally view or post in } \\
\text { threads, forums, chat rooms, or community } \\
\text { related sites }\end{array}$ & 10 & $18 \%$ \\
$\begin{array}{l}\text { 6 } \\
\text { 7: I regularly view or post in forums, blogs, } \\
\text { or chat rooms of the community }\end{array}$ & 3 & $5 \%$ \\
$\begin{array}{l}8 \\
\text { 9: I spend most of my time interacting with } \\
\text { the community }\end{array}$ & 4 & $7 \%$ \\
\hline
\end{tabular}

Regarding respondents' opinion of the tulpa community, $18 \%$ reported theirs as very positive, $52 \%$ chose positive, and $29 \%$ selected "neutral".

\subsection{Cross-Sectional Analysis}

The survey results clarify the existence of the two associations identified by Veissiere. A majority (56\%) of the sample reports being diagnosed with a mental or neurodevelopmental disorder, which is an exceptionally high frequency when compared to the United States' rate of $18.2 \%$ [13].

However, there was no evidence of tulpas causing or furthering cases of mental illness. In fact, the association between tulpas and improvements in mental health was reinforced, with $78 \%$ of these respondents diagnosed with a psychopathology stating that tulpas had either a significant or somewhat positive impact on their condition or ability to cope with it. $91 \%$ of the sample claimed that tulpas had a significant or somewhat positive impact on their overall life. $78 \%$ upheld the same for their mental health, and $47 \%$ reported this improvement for their social life.

\subsubsection{Tulpas and Mental Illness}

There was no evidence that would suggest tulpamancy is harmful. Most respondents with a psychopathology were diagnosed before the creation of a tulpa. The remaining cases were either unrelated to tulpas or resulted from the host becoming more aware of their condition.

The survey results reinforce the association between practicing tulpamancy and improvements in perceived mental health, socialization, and overall life. These facts should discourage hypotheses that suggest tulpas cause mental illness or are a disorder in and of itself. The survey data was analyzed to find if the perceived impacts of tulpas on social life, mental health, or overall life had any association to responses to other questions on the survey.

\subsubsection{Alternate Causation}

Concerns of alternate causation as outlined in section 1.2 ("Purpose") were investigated-- foremost, whether doing meditation as a part of one's tulpamancy practice affected the impact of tulpas on mental health. It was found that those who practiced both were slightly more likely to report a significant positive impact, but even so, most respondents cited a positive impact regardless of hypnosis and meditation use. So, while likely a plus, meditation is not solely responsible for improvements associated with tulpamancy (Figure 1).

There is also the possibility that a self-fulfilling prophecy principle is driving the reports of improvements. To address whether expecting tulpas to cause enhancements plays a role, the reason a respondent began practicing tulpamancy was compared to the impact of tulpamancy on their perceived mental health. Again, no association was found, with individuals who created their tulpa for "self-improvement or life/mental health benefits" reporting almost identical rates of improvements as ones who cited friendship, curiosity, or romance (Figure 2).

It was also considered that the improvements could be derived from the tulpa community. Most respondents were found to be somewhat involved in the community and hold a positive opinion of it, but these do not seem to be factors in the greater impact of tulpas. Once more, when impact was compared to the respondent's involvement and opinion of the tulpa community, no significant relationships were found (Figure 3). Those who had a "Very positive" opinion of the tulpa community were slightly more likely to report improvements in their social life, mental health, and overall life, but this association did not exist among those who had a "Positive" opinion. The online community, while a plus for some, is not responsible for the improvements associated with tulpas.

So, even when compared to a myriad of factors, the reported improvements in mental health, overall life, and social life seem unrelated to the most likely candidates of alternate causation. These associations appear to be phenomena specific to successfully creating a tulpa. 


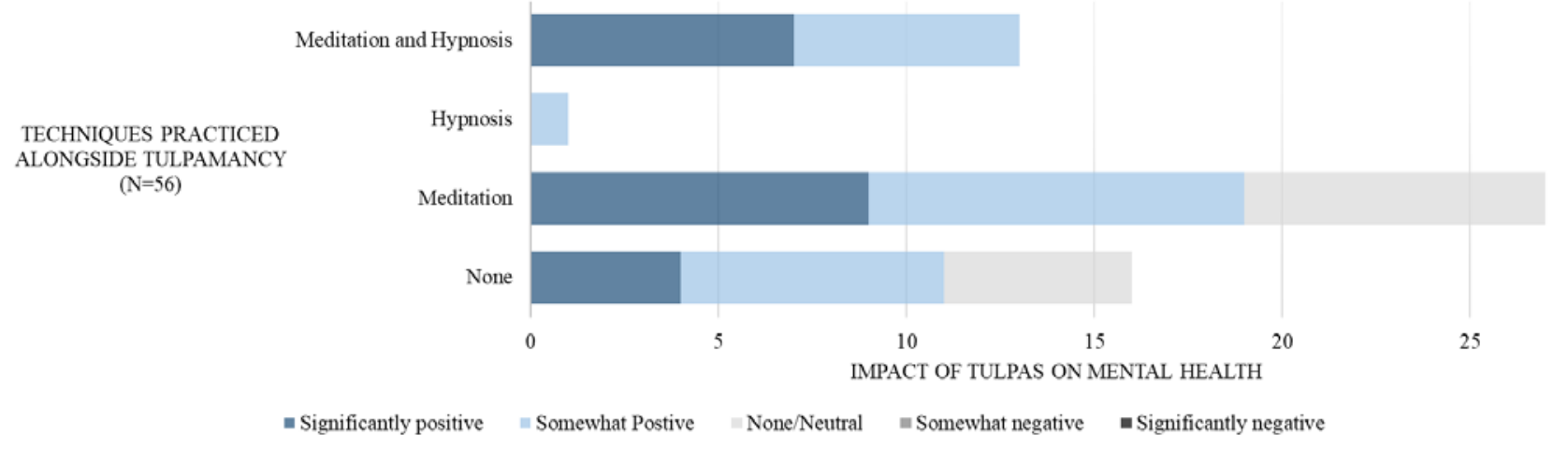

Figure 1. The Techniques Practiced Alongside Tulpamancy Versus the Impact of Tulpas on Mental Health

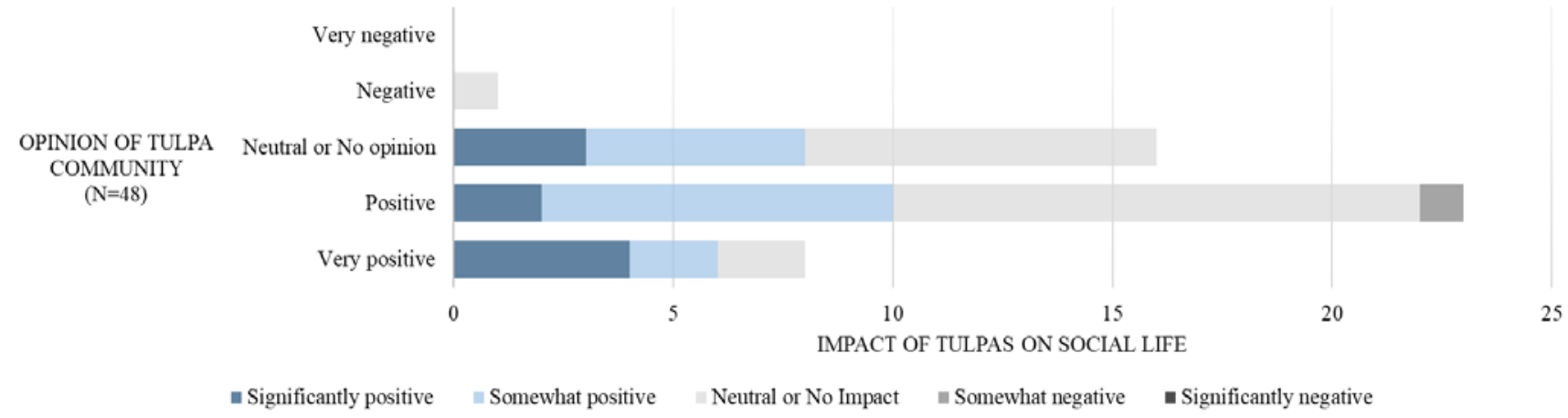

Figure 2. The Reason for Making Tulpas Versus the Impact of Tulpas on Mental Health

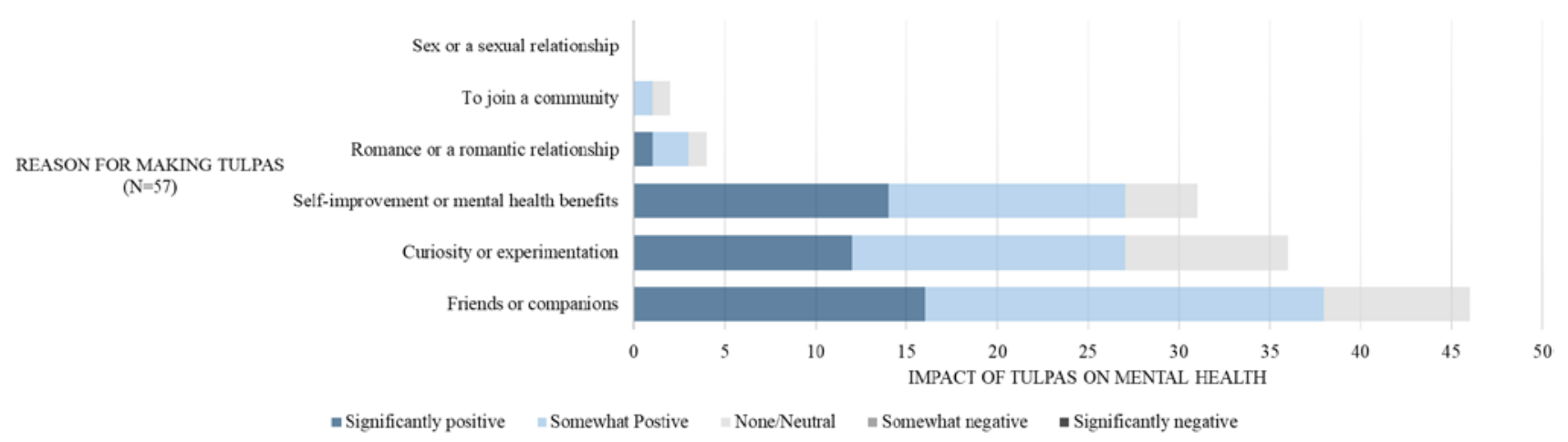

Figure 3. Opinion of Tulpa Community Versus the Impact of Tulpas on Social Life

\section{Discussion}

It is likely that the high frequency of disorders among tulpamancers is not caused by tulpamancy being pathological in nature, but rather, the practice being especially appealing towards those already diagnosed. The survey data supports this hypothesis: 66\% of respondents diagnosed with a psychopathology report that their disorder either somewhat or significantly furthered their decision to make a tulpa.

To make sense of this, consider two factors: first, that two of the most common diagnosis among tulpamancers are Social Anxiety Disorder and Autism Spectrum Disorder-conditions often associated with hindrances in interpersonal relationships. Second, that tulpas are advertised as being "the perfect kinds of companions" [7]. Tulpa.info, the flagship website for tulpamancy resources, elaborates on this. "A bond with one's tulpa is often extremely strong, because they can know you intimately, understand you, and generally like and trust you almost implicitly, and all this is due to them being in the brain with you. That allows them to understand you like no other person" [14]. In fact, the data not only suggests that tulpas may be more appealing to those struggling with a psychopathology, but that it is especially beneficial towards such individuals. $74 \%$ of respondents stated that their condition makes tulpamancy either a somewhat or significantly more desirable practice. Several diagnosed with Social Anxiety Disorder opted to elaborate on why this was the case for them. Tulpas not only provided a means to have pleasant, worry-free interactions in the safety of their own mind-for these hosts, tulpas also encouraged and assisted with socialization.

The notion of tulpas being intimate, trustworthy companions can also explain the association between tulpas and improvements in mental health. An overwhelming majority of tulpamancers develop strong and intimate bonds with their systemmates. Hosts consistently describe how their tulpas keep their best interests in mind and take steps to alleviate any ailments, mental or physical, that the host may have in their life. If a disorder is causing distress 
and one's tulpa happens to be independent from it (as they are, to some degree, in $85 \%$ of cases), then we would expect to see what we already observe: tulpas helping their host cope with mental illness.

At the end of each section of the survey, respondents were given the option to elaborate on their answers in short answer form. The responses were eye opening towards the diversity of impacts tulpas can have on mental illness. In cases of disorders that involve delusion and misperceptions, the tulpa often becomes the voice of reason during bouts of irrationality. One respondent diagnosed with Schizophrenia writes how his tulpa can not only identify between hallucination and actuality, but that they developed a technique that allows the delusions to be "zapped" away. There are reports of tulpas alleviating the desire to perform irrational routines in individuals diagnosed with OCD, and others claim that their tulpas innovated workarounds for their dyslexia. A system with DID even detailed how making a tulpa improved their functioning and ability to work together because the tulpa was unaffected by amnesia and could communicate otherwise unattainable information between alters.

In disorders where delusions are not a factor, tulpas still make their mark. Multiple respondents suffering from depression described how beneficial their tulpas were by simply providing their friendship and positive voices. Others discuss how their tulpas prevented their suicide, be it through words or acting to remove the host's control of the body.

The experience of having a warm relationship with one's tulpas is almost synonymous with tulpamancy practice itself. When combined with the more outstanding factors of tulpamancy, namely the perceived independence of tulpas from one's ailments, a relationship unlike any corporeal one forms. One respondent diagnosed with Schizophrenia phrases it like this: "I hear voices all the time. It's good to hear a nice one from a tulpa for a change.”

These contributing factors and outcomes of a positive tulpa experience are modeled in Figure 4.

\subsection{Limitations and Future Research}

It is important to acknowledge the limits of this study. The membership of just three tulpa sites were surveyed, with the tulpa reddit, tulpa.info forum, and newer Discord communities all being unincluded. Additionally, self-reported data gathered through online surveys, regardless of the care taken to ensure objectivity and accuracy, is bound to be influenced by biases and misconceptions. And, of course, the observational nature of this study means that causality cannot be proven.

The intent of this paper is not to provide definitive assertions on the psychology of tulpamancy. Rather, the purpose is to accentuate outstanding associations and suggest further research into them. Garnering an understanding of tulpa phenomena may not only allow us to identify and further apply its therapeutic properties, but also add to the understanding of the human cognition, its plasticity, and the nuances of psychopathology. The highest suggestion of this research is to further investigate tulpa and plural phenomena.

Because non-traumagenic plural experiences rarely affect functioning, they have fallen very much under the radar of researchers, academics, and mental health professionals. The existing body of research on non-DID plurality is limited to online surveys and theory, and this must change. The lack of social, scientific, and medical awareness and understanding of plurality causes stigmatization, misdiagnoses, and mistreatment. Further research is a necessity to counter this. In-person psychiatric assessments, longitudinal research, and neuroimaging studies are all more than warranted towards building a greater scientific understanding of plurality.

There are two accusations made towards tulpamancers that, despite having little base, are worth investigating. The first is the concern of falsification, which is founded on the idea that what tulpamancers experience is impossible for non-psychotic persons. In turn, tulpamancers are lying in order to fit in with the tulpa community. This hypothesis is unlikely-- it has been proven that "normal" people can give themselves hallucinated voices similar to tulpamancers [15], and as the results of this study demonstrate, tulpa experiences do not vary significantly between those who like, dislike, interact with, or avoid the community. Even so, it would not hurt to conduct a study to remove any remaining doubt.

The second accusation is that tulpamancers are, in fact, psychotic, and tulpas are a symptom of mental illness. To address this, full, in-person psychiatric assessments of tulpamancers, in addition to neuroimaging, would be desirable. Signs of psychosis being unveiled is a very unlikely, but potentially very useful, outcome, as tulpamancers would have found a way to make it a positive experience. A more likely outcome of this research would be an effective toolset for distinguishing pathology from benign voice-hearing and plural experiences.

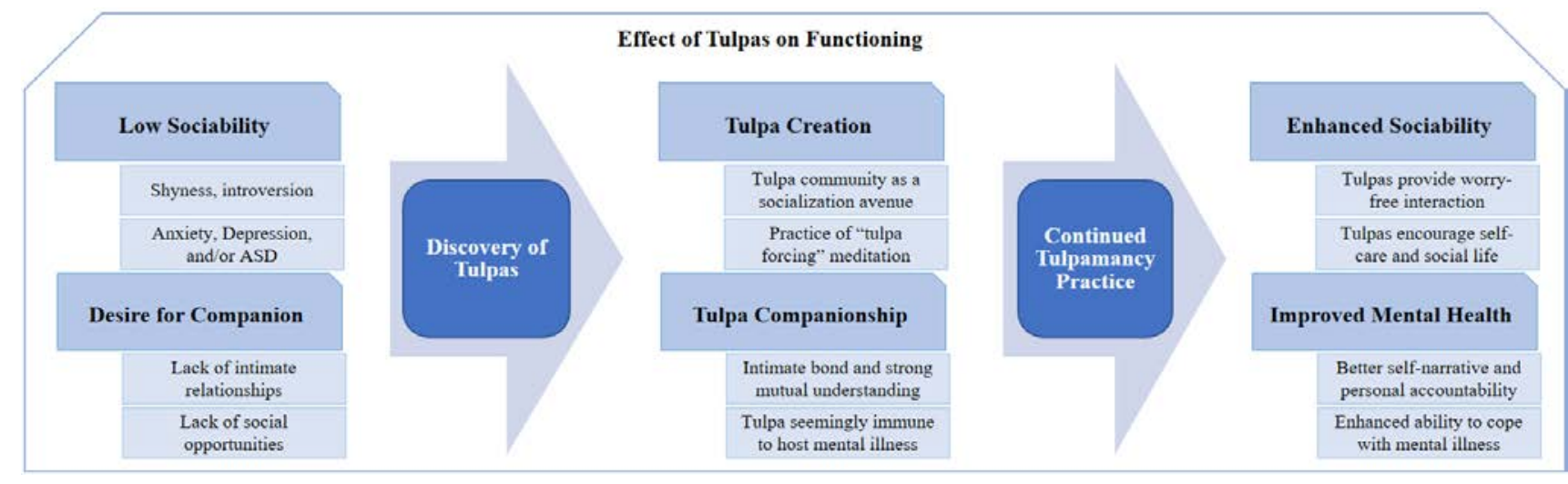

Figure 4. Model of the Effect of Tulpas on Functioning 


\section{Conclusions}

Tulpas are an experience of psychology and identity that, while being different from the norm, appears to be perfectly consistent with happiness, health, and functioning. Plurality isn't something that should be seen as disordered and needing correction. As tulpamancers demonstrate, it can even be beneficial in some circumstances. The concept that societies should embrace persons of alternate psychological variations rather than label them as disordered, inferior, and in need of becoming "normal" is dubbed Neurodiversity. This idea has been popularized by the ASD community, which purports that Autism is a condition that, rather than being inherently disordered, is more accurately an alternative state of human cognition with its own benefits and detriments for a modern Western life.

This mindset also benefits cases of plurality that are associated with a disorder. Dissociative Identity Disorder is misperceived as a condition rooted in its most outstanding symptom: multiplicity. In reality, DID is a traumagenic condition, with the multiplicity, amnesia, and other symptoms being a coping device or consequence of trauma or abuse [16]. The impact of trauma and the resulting function-impairing symptoms are what make DID a disorder, not the plurality [2].

Even in traumagenic plurality, accepting multiple identities as an experience of Neurodiversity rather than a symptom of an illness is preferable. Being plural often becomes an inexorable identity that is not only difficult to change, but makes attempts to do so harmful. Because of this, psychiatrists have found that the most effective therapies for DID do not require merging different consciousnesses or enforcing oneness. Rather, it is more effective to simply teach the separate identities to communicate, share information, and work with each other in through a therapy dubbed "integrated functioning" [17]. When given the option, only a minority of effectively treated DID patients choose to integrate [18]. The decision to unify should be an optional one, made by the patient, done because they believe it will improve their life and ability to function. The prevalence of treating plurality as the start and end to dysfunction in DID indicates a fundamental misunderstanding that needs to be corrected.

Plural experiences are not limited to tulpas and dissociative disorders. In fact, when the diversity of plural experience is considered, multiplicity may seem to be less of an extraordinary achievement and more of a fundamentally human experience. Many fiction writers, for example, report that the characters of their design seem to come to life in their heads, behaving autonomously and being perceived as full-fledged consciousnesses [19]. Religious individuals of faiths where the God, Gods, or spirits they believe in can interact with them to a degree report similar phenomena, regardless of their specific religion or culture $[20,21,22]$. There are also online communities tangential to tulpas where members report being plural as long as they can remember, but do not experience uncontrolled dissociation. And, of course, there is also tulpamancy. Tulpamancy is one way to willfully create new identities. It is a means to become plural.

Plurality, being deviant from the norm but with the potential of being a healthy, functional, and even optimal state of being, should be upheld with the advent of Neurodiversity. We ought to value diversity and acceptance over the enforcement of norms by including, rather than stigmatizing, the exceptional.

\section{Acknowledgements}

The tulpa and plural communities are a collection of weird and wonderful individuals. The community, the feedback it gives me, and many of its members have been my mentors more than anyone else. Without their generous participation, blunt feedback, and persistent support, this study would have never been actualized.

I'm grateful for every academic that's been willing to give myself or plurality an open ear. This same gratitude goes out to every openly plural individual-- there is a stigma attached to being multiple, and I commend the bravery of everyone willing to put their face behind it. With more research and public engagement, that social attitude will change.

Finally, I would like to thank the unsung assistant and co-author of my research, projects, and frankly, my life: my tulpa, Aury. Her behind-the-scenes efforts are the reason I'm functioning, and without her, I probably wouldn't be here today in any form.

\section{Statement of Competing Interests}

The author is a practicing tulpamancer and an active member of the tulpa community. He experienced tulpa creation firsthand in April 2013, and has been a contributing member of the online community since July 2014. Along with his tulpa, Aury, Isler is active under the usernames "Ford and Aury" and "fordaplot", through which they have shared their experiences, theories, and preliminary results with the community. They run a Tumblr blog documenting their tulpa-related work and experiences, and they operate a YouTube channel for plural-related educational videos, interview-based podcasts, and visual tulpamancy guides.

The author has no other competing interests.

\section{List of Abbreviations}
ADHD: Attention Deficit Hyperactivity Disorder
ASD: Autism Spectrum Disorder
DCD: Developmental Coordination Disorder
DSM: Diagnostic and Statistical Manual of Mental Disorders
DID: Dissociative Identity Disorder
IRC: Internet Relay Chat
OCD: Obsessive-Compulsive Disorder
PTSD: Post-Traumatic Stress Disorder

\section{References}

[1] Nijenhuis, E. R. S., Spinhoven, P., van Dyck, R., van der Hart, O. and Vanderlinden, J, "Degree of somatoform and psychological dissociation in dissociative disorder is correlated with reported trauma”, Journal of Traumatic Stress, 11, 711-730, October, 1998. 
[2] Kunzendorf, R.G., Crosson, M., Zalaket, A., White, J. Enik, R., "Normal Dimensions of Multiple Personality without Amnesia", Imagination, Cognition, and Culture, 18 (3), 205-220, March, 1999.

[3] PsychologyToday, Dissociative Identity Disorder, February, 2017. [Online] Available:

https://www.psychologytoday.com/conditions/dissociativeidentity-disorder-multiple-personality-disorder. [Accessed August. 24, 2017]

[4] Stein, D.J., Phillips, K.A., Bolton, D., Fulford, K.W.., Sadler, J.Z., Kendler, K.S., "What is a Mental/Psychiatric Disorder? From DSM-IV to DSM-V”, Psychological Medicine, 40 (11), 1759-1765. January, 2010.

[5] Clayton, K., "Critiquing the Requirement of Oneness over Multiplicity: An Examination of Dissociative Identity (Disorder) in Five Clinical Texts”, E-Journal of Applied Psychology: Clinical Section. 1(2): 9-19, December, 2005.

[6] American Psychiatric Association, Diagnostic and statistical manual of mental disorders: DSM-IV-TR, American Psychiatric Association, Washington, DC, 2000.

[7] Veissiere, S., "Varieties of Tulpa Experiences", Somatosphere: Science, Medicine, and Anthropology, April 2015.

[Online] Accessible: http://somatosphere.net/2015/04/varieties-oftulpa-experiences-sentient-imaginary-friends-embodied-jointattention-and-hypnotic-sociality-in-a-wired-world.html. [Retrieved September 7th, 2017].

[8] Baron-Cohen, S., Jolliffe, T., Mortimore, C., Robertson, M., "Another Advanced Test of Theory of Mind: Evidence from Very High Functioning Adults with Autism or Asperger Syndrome", The Journal of Child Psychology and Psychiatry, 38 (7), 813-822, October 1997.

[9] Lister Hill National Center for Biomedical Communications, “Asperger syndrome- Genetics Home Reference”, November 2016. [Online] Accessible: https://ghr.nlm.nih.gov/condition/aspergersyndrome [Accessed November 7, 2016]

[10] Center for Disease Control and Prevention, "ADHA Data \& Statistics”, 2016

[Online] Accessible: http://www.cdc.gov/ncbddd/adhd/data.html [Accessed November 7, 2016].

[11] National Institute of Mental Health, "Generalized Anxiety Disorder Among Adults”, 2016.

[Online] Accessible:

https://www.nimh.nih.gov/health/statistics/prevalence/generalizedanxiety-disorder-among-adults.shtml [Accessed November 7, 2016].
[12] Grossman, P., Niemann, L., Schmidt, S., \& Walach, H., "Mindfulness-based stress reduction and health benefits: A meta-analysis. Focus on Alternative and Complementary Therapies," 8 (4), 500-500. 2010.

[13] National Alliance on Mental Illness, B. T., Mental Health by the Numbers, January 2015.

[Online] Accessible: http://www.nami.org/Learn-More/MentalHealth-By-the-Numbers [Retrieved November 7, 2016].

[14] Tulpa.info. Why Have a Tulpa? 2014.

[Online]. Accessible: https://www.tulpa.info/why-have-a-tulpa/ [Accessed November 6, 2016].

[15] Powers, A.R., Mathys, C., Corlett, P.R., "Pavlovian conditioninginduced hallucinations result from overweighting of perceptual priors”, Science, 357 (6351), 596-600, August 2017.

[16] Gleaves, D.H., May, M.C., “An Examination of the Diagnostic Validity of Dissociative Identity Disorder”, Clinical Psychology Review, 21 (4), 577-608, 2001.

[17] International Society for the Study of Trauma and Dissociation, "Guidelines for Treating Dissociative Identity Disorder in Adults, Third Revision,” Journal of Trauma \& Dissociation, 12 (2), 115-187, 2011.

[18] Brand, B. L., Myrick, A. C., Loewenstein, R. J., Classen, C. C., Lanius, R., Mcnary, S. W., Putnam, F. W., “A survey of practices and recommended treatment interventions among expert therapists treating patients with dissociative identity disorder and dissociative disorder not otherwise specified." Psychological Trauma: Theory, Research, Practice, and Policy, 4 (5), 490-500, 2012.

[19] Taylor, Marjorie, Hodges, Sara D., Kohányi, A., "The Illusion of Independent Agency: Do Adult Fiction Writers Experience Their Characters as Having Minds of Their Own", Imagination, Cognition and Personality, 22 (4), 361-380, 2003.

[20] Luhrmann, T.M., “Conjuring Our Own Gods," The New York Times, October 2013.

[Online] Accessible: http://www.nytimes.com/2013/10/15/opinion/luhrmann-conjuringup-our-own-gods.html. [Accessed September 7, 2017].

[21] Luhrmann, T.M., When God Talks Back: Understanding the American Evangelical Relationship with God, Vintage Books, New York, 2012, 365.

[22] Isler, J.J., Luhrmann, T.M., God, Tulpas, and Schizophrenia: A Discussion with Stanford Professor Tanya Luhrmann, May 2017. [Online] Accessible: https://www.youtube.com/watch?v=9-QfbEVSLzA [Accessed September 7, 2017]. 